\title{
BMJ Open Knowledge and intake of folic acid among teachers of childbearing age in the State of Qatar: a cross- sectional study
}

\author{
Al Mannai Lolowa, ${ }^{1}$ Nagah Selim, ${ }^{\oplus 1,2}$ Mohammad Alkuwari, ${ }^{\oplus 1}$ \\ Mansoura Salem Ismail ${ }^{1,3}$
}

To cite: Lolowa AM, Selim N, Alkuwari M, et al. Knowledge and intake of folic acid among teachers of childbearing age in the State of Qatar: a crosssectional study. BMJ Open 2019;9:e025005. doi:10.1136/ bmjopen-2018-025005

- Prepublication history for this paper is available online. To view these files, please visit the journal online (http://dx.doi org/10.1136/bmjopen-2018025005).

Received 2 July 2018

Revised 11 January 2019 Accepted 5 March 2019
Check for updates

(C) Author(s) (or their employer(s)) 2019. Re-use permitted under CC BY-NC. No commercial re-use. See rights and permissions. Published by BMJ.

${ }^{1}$ Family \& Community Medicine, Primary Health Care Corporation, Qatar, Doha, Qatar

${ }^{2}$ Public Health and Preventive Medicine, Faculty of Medicine Cairo university, Cairo, Egypt

${ }^{3}$ Family Medicine, Faculty of medicine Suez Canal university, Ismailia, Egypt

Correspondence to Dr Mansoura Salem Ismail; msismail@phcc.gov.qa

\section{ABSTRACT}

Objectives To assess the knowledge and intake of folic acid among teachers of childbearing age and to identify barriers to folic acid intake.

Setting Governmental schools, which included 14 primary models, 29 primary, 14 preparatory and 16 secondary schools. The proportion of teachers in each stratum was then determined, and a stratified random sampling design had been used with proportional allocation.

Study design Cross-sectional study

Participants A total of 406 non-pregnant teachers of childbearing age enrolled in the study. A validated questionnaire in the Arabic language was used.

Results The overall response rate was $98 \%$. About $34.6 \%$ reported the optimal period in which they should take folic acid, $28.3 \%$ reported the correct intake duration and only $29.5 \%$ could name food rich in folic acid. Friends and healthcare providers were the main sources of information for the participants; however, $44 \%$ said that they did not receive enough information from their healthcare providers.

Conclusion There is a lack of knowledge and poor intake of folic acid among the participants. In particular, they lacked information about the appropriate time to start folic acid supplementations, the duration of intake and the folic acid-rich food. The most common reason being the limited advice given by their healthcare providers. Awareness campaigns are recommended to emphasise the role of healthcare providers in counselling women about the proper use of folic acid before pregnancy.

\section{INTRODUCTION}

Birth defects have so far been the leading cause of infant mortality for the past 25 years, causing $22 \%$ of all infant deaths. Infants with neural tube defects (NTDs) continue to be at increased risk of morbidity and mortality, resulting in approximately 88000 deaths and 8.6million disability-adjusted life years. ${ }^{1-5}$ NTDs are a serious group of heterogeneous and complex congenital birth defects of the brain and spine. They are considered to make up one of the highest incidence rates of all congenital malformations. NTDs rates differ
Strengths and limitations of this study

- This is the first population-based study among teachers assessing their knowledge and intake of folic acid in Qatar.

- Teachers are considered role models by their students and they have a unique opportunity to reinforce thoughts and ideas among students and community. They are a well-defined group with reasonable socioeconomic status and accessible.

- The level of awareness and knowledge about folic acid might be related to the selection of a highly educated subject group.

- This is a cross-sectional study where temporality cannot be demonstrated.

- With the self-reporting nature involved in gathering this data, there is the danger of recall bias and participants may have over-reported or under-reported their knowledge about or use of folic acid supplements. The teachers in this study may not represent all women of childbearing age and therefore, the generalisability of these results may be limited.

from one population to another and have been found to vary according to geography, time and selected maternal demographic characteristics. ${ }^{6-8}$ According to the International Clearinghouse for Birth Defects Surveillance and Research, the prevalence rates of NTDs-including spina bifida, anencephaly and encephalocele-between 2007 and 2011 were 5.14 per 10000 live births and stillbirths in Canada, 6.85 in Japan and 7.64 in the US state of Texas. ${ }^{9}$ The European Surveillance of Congenital Anomalies found the prevalence of NTDs in European countries between 2008 and 2012 to be 9.69 per 10000 births. ${ }^{10}$ The incidence of NTDs in the United Arab Emirates (UAE) was 11.4 per 10000 live births; with approximately 50000 live births annually in the UAE, it is expected that around 57 babies are born with NTDs every year. If folic acid supplements can prevent half of these 
cases that would mean a reduction of about 30 cases of NTD annually. ${ }^{11}$ In Oman, national data retrieved from hospital records showed the incidence of NTDs to be 12.5 per $10000 .^{12}$

Folic acid reduces the risk of birth defects, including NTDs. It also decreases the risk of miscarriage and fetal death as well as folate-deficiency anaemia. ${ }^{13-15}$ Folate status is particularly important before conception and during the first 12 weeks of pregnancy. Despite the increasing awareness of the need for NTD prevention, studies have reported that folic acid intake by non-pregnant women, especially young women taking daily multivitamin supplements containing folic acid, is still low. ${ }^{16} 17$ Different reports show women who were aware of the need for folic acid were almost 40 times more likely to take it than women who did not know of its benefit. ${ }^{18}$

Food fortification has been undertaken in the Arab Gulf Region since the late 1970s. In the 1990s, several countries in the region began fortifying wheat flour with encouragement from international organisations, such as the WHO, the United Nations Children's Fund and the Micronutrient Initiative. Fortification of wheat flour with iron and folic acid is mandatory in Kingdom of Saudi Arabia, Oman, Kuwait and Bahrain, and voluntary in Qatar. In the year 2000, Qatar started adding $30 \mathrm{mg}$ of iodine and 1.5-2 mg of folic acid to wheat flour. Non-pregnant women of childbearing age reported an average daily consumption of $128 \mu \mathrm{g}$ of folic acid, only $32 \%$ of the daily recommended amount. Investigations determined that at the present level of folic acid fortification most women still need to consume folic acid-containing dietary supplement daily to achieve the 400 micrograms per day as recommended. Thus, supporting the need for continuing the promotion of folic acid supplementation, especially in a developing country, such as Qatar. ${ }^{19}$

Female teachers are a well-defined group with good socioeconomic status, well-educated, they are accessible, and proposed target for intervention. They are role models for their students and could reinforce thoughts and ideas among them. There is a lack of data available about folic acid awareness or intake among teachers of childbearing age in the State of Qatar.

\section{Objectives}

This study aims to assess the knowledge and intake of folic acid among teachers of childbearing age and to identify barriers to folic acid intake.

\section{METHODS}

\section{Study design}

Cross-sectional study

\section{Setting}

The study was conducted in governmental schools. According to the Ministry of Education, there are four educational regions in Qatar, represented as follows: Doha Region, Dukhan Region, Al Shamal Region and Al
Khor Region. These four areas included all the governmental schools with different educational levels (primary model, primary, preparatory and secondary levels). These levels are distributed in 73 schools, most of these schools (approximately 56) are located inside Doha city as it's the largest city in Qatar with majority of the population $(90 \%)$ living in it.

\section{Sample size}

The sample size was calculated by Open Epi Info software (V.10), based on $53.7 \%$ expected proportion (effect size) of folic acid awareness, 95\% CI and 0.05 absolute precision on either side of the proportion $\mathrm{p}(d)$ were used.

Estimated sample $(n)=338$, after addition of $20 \%$ to compensate for non-response, the final sample $(n)=406$.

\section{Sampling technique}

A total number of 3757 teachers were employed in governmental schools and the eligible number of teachers were 2913. A stratified random sampling design was used with proportional allocation. First, the schools were divided into four different strata according to the educational level (primary model, primary, middle and high schools); the sample included 14 primary models, 29 primary, 14 preparatory and 16 secondary schools. The proportion of teachers in each stratum was then determined, and a simple random sampling was conducted to select the eligible teachers from each stratum.

\section{Inclusion criteria}

Teachers of childbearing age $\leq 49$ years old working in the selected schools at different educational levels.

\section{Exclusion criteria}

Teachers who are pregnant and those who are on leave when the study is conducted.

\section{Outcome variables}

Knowledge of folic acid and its intake before pregnancy

\section{Potential determinants}

Sociodemographic factors including age, marital status and nationality, socioeconomic status including family income and educational level, and finally, the relationship between knowledge and intake of folic acid

\section{Method of data collection tool}

A self-administered questionnaire in the Arabic language was developed by the researchers after reviewing the literature. ${ }^{16} 20-23$ The questionnaire included sociodemographic data, such as age, nationality, marital status, educational level, place of work and family income. It also included questions concerning knowledge about folic acid as a vitamin, its role in the prevention of NTDs, the frequency, the duration and appropriate intake time. Other questions assessed their knowledge around the sufficiency of food as a source of folic acid and it also examined their intake of folic acid supplements in addition to food rich in folic acid as well as the participants' 
source of information regarding these. There were also questions to determine their folic acid intake $(400 \mu \mathrm{g}$ as recommended daily) at the time when the survey was conducted even if they took it as a one-off on the day. The final questions assessed the barriers related to folic acid intake. The questionnaire was pretested with a convenient sample of the study population $(n=41$ female teachers), and some questions were modified based on the feedback from the pilot testing. Teachers who participated in the pilot were excluded from the sampling frame when selecting the study subjects.

The findings of this study are subject to certain bias as it's based on self-reported information; therefore, findings might be overestimated or underestimated. However, we are convinced with the results since it's unlikely that the participants spent time giving unreliable answers especially with full explanation of the importance and confidentiality of data here as well as anonymity of the survey.

\section{Data management}

The data were analysed using SPSS, Windows, V.20. $\mathrm{X}^{2}$ tests of significance and/or Fisher's exact test were performed to test relationships between proportions. A value of $\mathrm{p}<0.05$ was considered the cut-off value for significance.

\section{Ethical consideration}

Voluntary participation and confidentiality were assured.

\section{PATIENT AND PUBLIC INVOLVEMENT}

The research questions were developed utilising the published literature on the importance of folic acid, the level of awareness surrounding it and its intake. Teachers' priorities, experiences and preferences were neither directly gathered nor involved in designing the study. There are no plans to disseminate results to the study participants directly. However, it is likely that the study participants will become more aware of it in the future.

\section{RESULTS}

In total, 406 female teachers were surveyed about their folic acid knowledge and intake for a period of 3 months, 400 participants completed and returned the questionnaires, giving an overall response rate of $98 \%$. Respondents' mean age was $35 \pm 5.65$ years. Of the teachers surveyed, Qatari female teachers constituted the majority $(89 \%)$ and $79 \%$ of participants were married. Family income per month ranged between 20001 and $30000 \mathrm{QR}$ for $47.3 \%$ of participants, with a median income of 22000 QR (table 1). Of the respondents, $88 \%$ had heard of folic acid and more than half of them had heard of NTDs. Concerning participants' knowledge about the timing of folic acid intake, $53.5 \%$ answered that they knew this but only $34.6 \%$ accurately reported the best time to take it, which is prior to conception and during the first trimester

\begin{tabular}{|c|c|c|}
\hline Characteristics & $\mathbf{N}$ & $\%$ \\
\hline \multicolumn{3}{|l|}{ Age } \\
\hline$\leq 35$ years & 202 & 50.5 \\
\hline \multirow[t]{2}{*}{$>35$ years } & 198 & 49.5 \\
\hline & \multicolumn{2}{|c|}{ Mean $\neq$ SD $35.59 \pm 5.654$} \\
\hline \multicolumn{3}{|l|}{ Nationality } \\
\hline Qatari & 356 & 89 \\
\hline Non-Qatari & 40 & 10 \\
\hline Missing & 4 & 1 \\
\hline \multicolumn{3}{|l|}{ Marital status } \\
\hline Married & 316 & 79 \\
\hline Non-married & 83 & 20.8 \\
\hline Missing & 1 & 0.2 \\
\hline \multicolumn{3}{|l|}{ Educational level } \\
\hline College level & 371 & 92.8 \\
\hline Postgraduate education & 28 & 7 \\
\hline Missing & 1 & 0.2 \\
\hline \multicolumn{3}{|l|}{ Place of work } \\
\hline Model schools & 45 & 11.2 \\
\hline Primary schools & 246 & 61.5 \\
\hline Preparatory schools & 44 & 11 \\
\hline Secondary schools & 65 & 16.3 \\
\hline \multicolumn{3}{|l|}{ Family income } \\
\hline$\leq 20000$ & 165 & 41.3 \\
\hline $20001-30000$ & 189 & 47.3 \\
\hline \multirow[t]{2}{*}{$>30000$} & 46 & 11.4 \\
\hline & \multicolumn{2}{|c|}{ Median=22000 } \\
\hline
\end{tabular}

of pregnancy (table 2). Regarding the origins of their knowledge, $60 \%$ reported that they received this advice from the women's hospital, while only $27 \%$ received advice from their primary healthcare and the remaining $13 \%$ from private health sectors. The majority of respondents $(90.9 \%)$ were advised to take folic acid supplementation by their doctor who attended to them during their antenatal visits, $6.2 \%$ received advice from the nurses and very few respondents received this information from a dietician (2.9\%). More than two-thirds of participants $(72.5 \%)$ had been advised about folic acid supplementation before the survey (table 3), but only $29.5 \%$ of participants mentioned that they knew which foods are rich in folic acid. About $32 \%$ answered that dietary folate is a sufficient source for the daily requirement of folic acid. Approximately, $78 \%$ of participants reported that taking both folic acid supplementations and food items rich in folate are beneficial (table 4). It was found that $74.5 \%$ had received folic acid pills at some point in time and $52.5 \%$ were taking folic acid supplements at the time of the study. Among those who took folic acid at some 
Table 2 Frequency distribution of participants according to awareness of folic acid (FA) and neural tube defects (NTDs)

\begin{tabular}{lcc}
\hline Knowledge & N & $\%$ \\
\hline Ever heard of FA & & \\
\hline Yes & 352 & 88 \\
\hline No & 48 & 12 \\
\hline Total & 400 & 100 \\
\hline Ever heard of NTDs & \\
\hline Yes & 211 & 52.8 \\
\hline No & 189 & 47.2 \\
\hline Total & 400 & 100 \\
\hline Awareness of preventive role of FA & & \\
\hline Yes & 162 & 76.7 \\
\hline No & 49 & 23.3 \\
\hline Total & 211 & 100 \\
\hline Do you know the time of FA intake & & \\
\hline Yes & 214 & 53.5 \\
\hline No & 186 & 46.5 \\
\hline Total & 400 & 100 \\
\hline Best time of FA intake & & \\
\hline Yes & 74 & 34.6 \\
\hline No & 140 & 65.4 \\
\hline Total & 214 & 100 \\
\hline Duration of FA intake & & \\
\hline Yes & 113 & 28.3 \\
\hline No & 287 & 71.7 \\
\hline Total & 400 & 100 \\
\hline Frequency of FA intake & & \\
\hline Daily & & \\
\hline Weekly & & 150 \\
\hline Monthly & & 5 \\
\hline Total & & \\
\hline & & \\
\hline
\end{tabular}

point in their lives, $55.4 \%$ took it daily; $80.2 \%$ of them were taking supplements in response to medical advice and $11 \%$ were taking it based on the advice of family and friends (table 5).

Marital status was the only statistically significant sociodemographic characteristic of the study population affecting their awareness $(\mathrm{p}=0.025$; see table 6$)$ and use of folic acid, with $81.6 \%$ of married women stating that they took folic acid pills $(p=0.001$; see table 7 ). A statistically significant relationship was established between folic acid awareness and its intake, whereby $81.8 \%$ of participants who were aware of folic acid took it as a supplement, and $88.9 \%$ of those who knew of its preventative role took folic acid supplements as a result. Of the teachers surveyed, $91 \%$ knew when to take folic acid, while $94.6 \%$ and $87.6 \%$ of those who knew the best time and the ideal duration of folic acid intake, respectively, had taken folic acid as a supplement at some point in time. Only $82 \%$ of
Table 3 Frequency distribution of participants who were advised about folic acid (FA), according to source and clarity of advice

\begin{tabular}{lrc}
\hline & N & $\%$ \\
\hline Source of advice & & \\
$\quad$ Primary health care & 69 & 27 \\
\hline Women's hospital & 152 & 60 \\
\hline Private hospital & 34 & 13 \\
\hline Person who gave the advice & & \\
$\quad$ Doctors & 232 & 90.9 \\
$\quad$ Nurses & 16 & 6.2 \\
\hline Dietitian & 7 & 2.9 \\
Clarity of advice & & \\
$\quad$ Clear & 188 & 73.7 \\
$\quad$ Unclear & 67 & 26.3 \\
$\quad$ Total & 255 & 100 \\
\hline Ever advised about FA & & \\
Yes & 255 & 72.5 \\
$\quad$ No & 97 & 27.5 \\
$\quad$ Total & 352 & 100 \\
\hline
\end{tabular}

teachers who knew the ideal frequency of folic acid intake had ever taken folic acid supplements. There is a statistically significant relationship $(\mathrm{p}<0.05)$ between knowledge about folic acid and being a current user of folic acid supplements; current use was particularly related to awareness of it, its preventive role, when to take it and the ideal duration of use (table 8). Concerning participants' intake of folate-rich food, the highest proportion $(43.8 \%)$ included cereals in their regular diet, followed by corn and spinach, kiwi was consumed the least $(27.8 \%$

Table 4 Frequency distribution of participants according to their knowledge of food rich in folic acid (FA) $(n=400)$

\begin{tabular}{lcc}
\hline Knowledge & N & $\%$ \\
\hline Knew some foods rich in FA & & \\
Yes & 118 & 29.5 \\
No & 282 & 70.5 \\
Thought folate in food is a sufficient source & & \\
$\quad$ Yes & 138 & 34.5 \\
$\quad$ No & 262 & 65.5 \\
Taking both food rich in folate and folic acid & & \\
pills are beneficial & & \\
$\quad$ Yes & 311 & 77.8 \\
$\quad$ No & 89 & 22.2 \\
\hline Source of information about folate-rich foods & \\
$\quad$ Family & 30 & 7.6 \\
\hline Friends & 183 & 45.7 \\
\hline Healthcare providers & 183 & 45.7 \\
\hline Media & 4 & 1 \\
\hline
\end{tabular}


Table 5 Frequency distribution of participants according to whether they had ever taken folic acid (FA), current users, and for what reason

\begin{tabular}{llc}
\hline Folic acid intake & N & $\%$ \\
\hline $\begin{array}{l}\text { Currently taking folic acid supplements* } \\
\text { Yes }\end{array}$ & 210 & 52.5 \\
No & 190 & 47.5 \\
\hline Have ever taken folic acid supplements & & \\
Yes & 289 & 74.5 \\
No & 102 & 25.5 \\
\hline Total & 400 & 100 \\
\hline
\end{tabular}

How frequently did you take folic acid

supplementsł

\begin{tabular}{lrc}
\hline Daily & 165 & 55.4 \\
\hline Weekly & 99 & 33.2 \\
\hline Monthly & 34 & 11.4 \\
\hline Reason for taking FA supplements & & \\
\hline Medical advice & 223 & 80.2 \\
\hline Family/friends advice & 33 & 11 \\
\hline Self-initiation & 26 & 8.8 \\
\hline Total & 298 & 100 \\
\hline
\end{tabular}

${ }^{*}$ Currently using it.

†Took folic acid before.

†Frequency of using folic acid before.

each; see figure 1). The most common barrier to folic acid intake (for $62 \%$ of respondents) was limitation of personal information about folate, while $9.2 \%$ of participants mentioned that because they were already taking many pills, they did not want to take additional supplements. About $44 \%$ said that they did not get enough information from their healthcare providers (figure 2).

\section{DISCUSSION}

Periconceptional folic acid supplementation is effective in the prevention of NTDs and other congenital abnormalities and can assist in the reduction of infant morbidity and mortality. It is, therefore, important to estimate knowledge and intake of folic acid among women of childbearing age. ${ }^{24} 25$ The current study showed that the overall awareness about folic acid was relatively high; $88 \%$ of participants reported that they had heard of folic acid at some point. This may be as a result of the participants' education level (almost all of them were college educated and higher) and three-quarters of them were married (approximately $75 \%$ were married); this comes in agreement with results from previous studies that showed that there was a direct association between educational level of women of childbearing age and their knowledge and intake of folic acid, where fortification strategies were found to offer the most cost-effective route to improve folic acid intakes and status. ${ }^{26} 27$

There's a clear contrast here to a study conducted in Saudi Arabia among female college students, which
Table 6 Relation between sociodemographic characteristics and awareness about folic acid $(n=400)$

\section{Ever heard of folic acid}

\begin{tabular}{|c|c|c|c|}
\hline \multirow[b]{2}{*}{ Characteristics } & Yes & No & \multirow[b]{2}{*}{$P$ value } \\
\hline & N (\%) & $\mathbf{N}(\%)$ & \\
\hline \multicolumn{4}{|l|}{ Age } \\
\hline$\leq 35$ years & $183(90.6)$ & $19(9.4)$ & \multirow[t]{2}{*}{$0.10^{*}$} \\
\hline$>35$ years & $169(85.4)$ & 29 (14.6) & \\
\hline \multicolumn{4}{|l|}{ Nationality } \\
\hline Qatari & $311(87.4)$ & 45 (12.6) & \multirow[t]{2}{*}{$0.15 \dagger$} \\
\hline Non-Qatari & 38 (95.0) & $2(5.0)$ & \\
\hline \multicolumn{4}{|l|}{ Marital status } \\
\hline Married & $284(89.9)$ & $32(10.1)$ & \multirow[t]{2}{*}{$0.025^{\star}$} \\
\hline Non-married & 68 (81.0) & 15 (19.0) & \\
\hline \multicolumn{4}{|l|}{ Educational level } \\
\hline College & 327 (88.1) & $44(11.9)$ & \multirow[t]{2}{*}{$0.86 \dagger$} \\
\hline $\begin{array}{l}\text { Postgraduate } \\
\text { education }\end{array}$ & 25 (89.3) & $3(10.7)$ & \\
\hline \multicolumn{4}{|l|}{ Place of work } \\
\hline Model schools & 43 (95.6) & $2(4.4)$ & \multirow[t]{4}{*}{$0.32 \dagger$} \\
\hline Primary schools & $200(88.1)$ & 46 (11.9) & \\
\hline $\begin{array}{l}\text { Preparatory } \\
\text { schools }\end{array}$ & $38(86.4)$ & $6(13.6)$ & \\
\hline $\begin{array}{l}\text { Secondary } \\
\text { schools }\end{array}$ & 55 (84.5) & $10(15.5)$ & \\
\hline \multicolumn{4}{|l|}{ Family income } \\
\hline$\leq 20000$ & $151(91.5)$ & $14(8.4)$ & \multirow[t]{3}{*}{$0.18 \dagger$} \\
\hline $20001-30000$ & 161 (85.2) & $28(14.8)$ & \\
\hline$>30000$ & 43 (93.5) & $3(6.5)$ & \\
\hline
\end{tabular}

${ }^{*} X^{2}$ test.

†Fisher's exact test.

showed that a much lower percentage $(12 \%)$ were aware of the importance of folic acid. ${ }^{28}$ Our findings are consistent with the findings of Hassan's study (2008), which was conducted in Qatar to assess folic acid intake among pregnant Qataris, of whom 94.0\% were aware of folic acid. ${ }^{29}$ The current study showed that slightly more than half of the participants had heard about NTDs at some time and of these, only $23.3 \%$ of the participants lacked awareness of its preventative role in reducing these birth defects. This is in contrast with a survey undertaken in the USA, which indicated that $75 \%$ of reproductive-aged women had heard of folic acid, but only $14 \%$ knew that it prevented birth defects. ${ }^{30}$ The study by Chacko et al found that half of the young women knew the role of folic acid in the prevention of birth defects. ${ }^{31}$

The current study shows that around one-third of the participants could identify the correct time to start taking folic acid and the duration of intake, with half of them currently using folic acid. This finding comes in agreement with a retrospective hospital-based cohort study, 
Table 7 Relation between sociodemographic characteristics and folic acid intake $(n=400)$

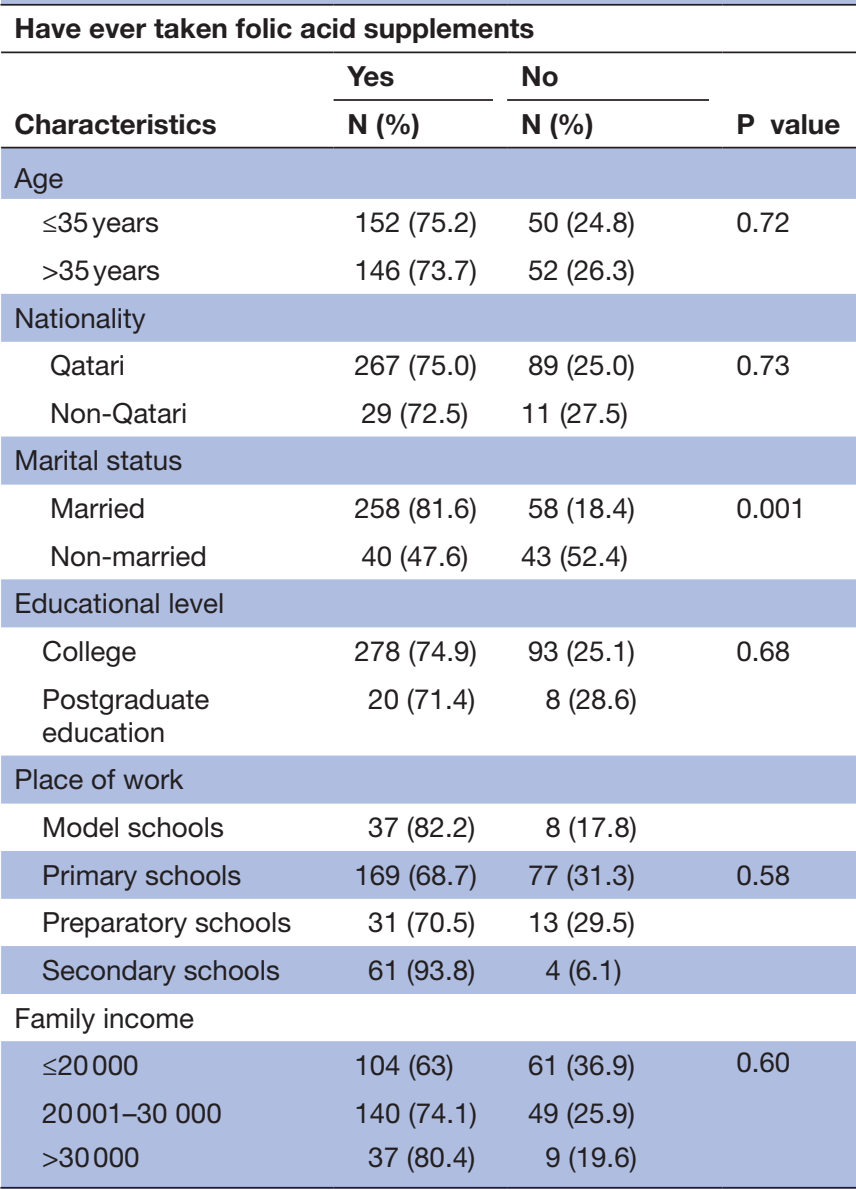

which was done to determine the trends of NTD over a period of 25 years. The study reported NTD in 1.09 per 1000 births, with high rates of consanguinity and lack of correct intake of folic acid among mothers being major factors contributing to NTD in Qatar. ${ }^{32}$

This study's findings were less than the results from the survey conducted in New Zealand, which showed that among women with planned pregnancies, 98.0\% had heard of folic acid, $63.6 \%$ knew that folic acid could prevent birth defects and $77.4 \%$ knew the appropriate time to take folic acid. ${ }^{33}$ Intake of food rich in folic acid as part of the weekly regular diet was assessed among the

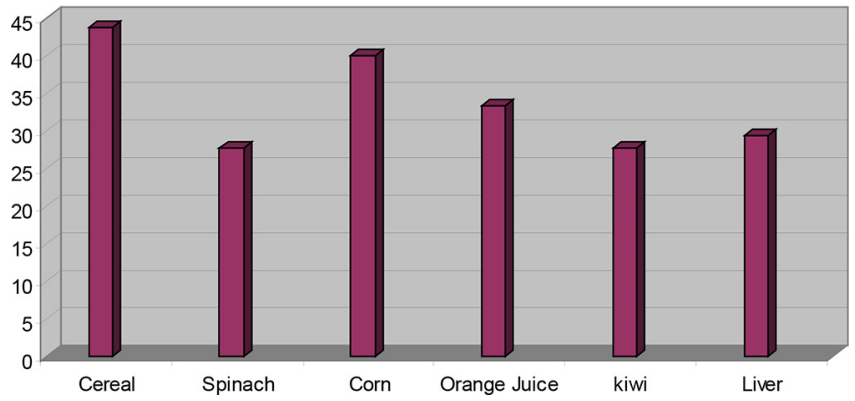

Figure 1 Distribution of participants according to the intake of folate-rich food items $(n=400)$.

participants, $43.8 \%$ included cereal in their regular diet; these results support those of Chacko et al, who found that cereal was the most frequently consumed folaterich food, but only $37 \%$ reported adequate frequency of cereal intake. ${ }^{31}$

A comparative analysis of strategies to improve folic acid intake concluded that dietary education to change dietary habits is difficult, and often food sources of individual micronutrients are limited. Encouraging use of nutritional supplements is plagued by low adherence rates and fortification strategies were found to offer the most cost-effective route to improve folic acid intake and status. $^{34}$

Fortification of cereal grain products with folic acid began in the USA, contributing to a $36 \%$ reduction in NTDs between 1996 and 2006: preventing an estimated 10000 NTD-affected pregnancies in a decade..$^{35}$ The same founded that the prevalence of NTDs declined from 2.6 per 1000 live births to 0.9 per 1000 live births. ${ }^{36}$

In this study, the younger teachers aged 35 years or below were more aware about the effects of folic acid than the older teachers. This agrees with the findings from the study by Bonin, which showed that knowledge was highest among the same younger age group. ${ }^{23}$

According to the results of our study, being married was significantly associated with better knowledge about folic acid, which can be due to the married women's previous experiences of pregnancy. This is similar to the findings of Sen $e t a l$, which found that majority of women of childbearing age $(91 \%)$ who are aware of folic acid were married. ${ }^{37}$ Our study's results are also similar to those of

Table 8 Relation between knowledge and practice of folic acid (FA) intake

\begin{tabular}{|c|c|c|c|c|c|}
\hline \multirow[b]{2}{*}{ Knowledge } & \multicolumn{2}{|c|}{ Currently taking FA supplementation } & \multicolumn{2}{|c|}{ Have ever taken FA supplementations } & \multirow[b]{2}{*}{$P$ value } \\
\hline & Yes (\%) & No (\%) & Yes(\%) & No (\%) & \\
\hline Ever heard FA & 201 (57.1) & $151(42.9)$ & $288(81.8)$ & 64 (18.2) & $<0.05$ \\
\hline Knew FA preventive role & $109(67.3)$ & $53(32.7)$ & $144(88.9)$ & $18(11.1)$ & $<0.05$ \\
\hline Knew when to take FA & $134(62.6)$ & $80(37.4)$ & $195(91.1)$ & $19(8.9)$ & $<0.05$ \\
\hline $\begin{array}{l}\text { Knew the best time to take } \\
\text { FA }\end{array}$ & $44(59.5)$ & $30(40.5)$ & $70(94.6)$ & $4(5.4)$ & $<0.05$ \\
\hline Knew duration to take FA & $76(67.3)$ & $37(32.7)$ & $99(87.6)$ & $14(12.4)$ & $<0.05$ \\
\hline Knew frequency & 191 (59.9) & $129(40.1)$ & $264(82.8)$ & $56(17.2)$ & $<0.05$ \\
\hline
\end{tabular}




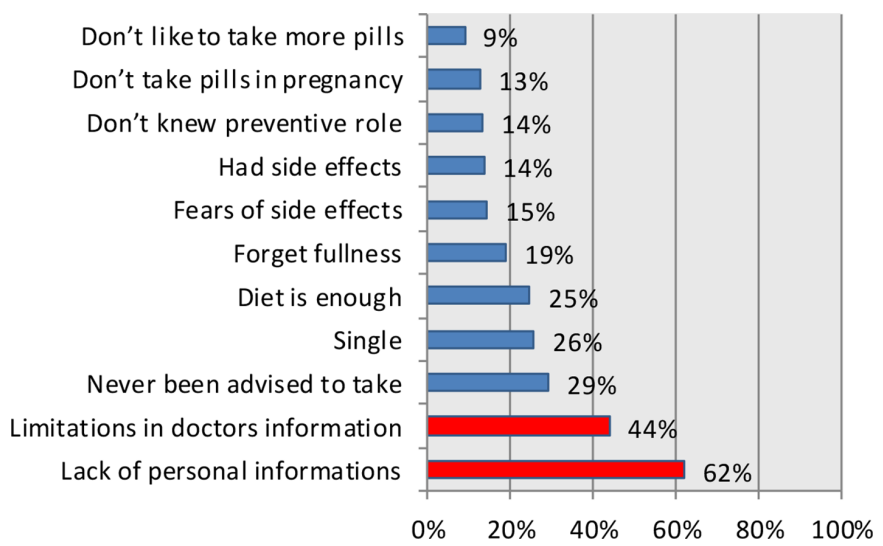

Figure 2 Barriers related to folic acid intake.

a survey conducted among Irish women of childbearing age, which showed no statistical association between age, education level and family income in relation to folic acid intake. ${ }^{30}$ A comparison of our results with a survey conducted in the USA shows that there are statistically significant differences regarding knowledge of folic acid and folic acid supplement consumption, and that these differences are observed more among the age group between 25 and 34 years, women with the highest incomes and those with higher levels of education. ${ }^{38}$

The majority of participants in the current study recall hearing about folic acid from their doctors $(90.9 \%)$ and their intake of folic acid supplements was dependent on medical advice, with $80.2 \%$ reporting that their intake was a result of a doctor's advice. Both friends (45.7\%) and healthcare providers $(45.7 \%)$ were the most frequent sources of participants' knowledge on folate-rich foods. This is higher than that found in the study by Chacko $e t$ $a l$, which showed that the health sector in general $(44 \%)$ and doctors in particular $(27 \%)$ were the most common sources of information about folic acid. ${ }^{31}$ This shows that healthcare systems still have an opportunity to reach more women with advice surrounding the intake of folic acid in the periconceptional period, which is supported by the study of Sayers $e t a l$, where only a few women $(8.7 \%)$ had received advice on taking folic acid before becoming pregnant. $^{39}$

Our study showed that folic acid intake among participants was related in a statistically significant fashion with their awareness; $81.8 \%$ of participants who knew the recommended frequency of folic acid intake reported that they had used folic acid, and $49.3 \%$ of these were taking folic acid daily. This contrasts the results of the study by Chacko et al, which found that only $9 \%$ of young women reported taking a daily multivitamin, and a very small number took daily multivitamins to prevent birth defects. $^{31}$

The rate of adequate supplement frequency was much higher in our study compared with that of Robert, which found that among the $77 \%$ of women who had heard about the benefits of folic acid only $26 \%$ reported that they took it daily as recommended. ${ }^{39}$ This agrees with the survey conducted among Irish women of childbearing age, which showed that despite a high level of knowledge about folic acid, the current daily intake of folic acid was still very low ${ }^{30} 40$. Another study showed that even though women aware of folic acid knew that they had to start taking it before conception, the majority still did not use it in the correct period. ${ }^{41}$

One of the limitations of the current study that planning for pregnancy, parity and history of a previous baby with anomalies (NTDs) were not studied, which might affect women knowledge and practice regarding folic acid. $^{42}$

Despite that the participants in the current study were well-educated and well-off population, the right knowledge and intakes of folic acid supplementation including doses and duration still were not sufficient, which came in agreement with findings from a previous study that showed half of the studied group had correct knowledge whereas only $27 \%$ of women reached the recommended $0.4 \mathrm{mg} /$ day. ${ }^{27}$ This suggests that there are still opportunities for more comprehensive patient education.

In the current study self-reported nature of the data, there is also the danger of recall bias, and participants may have over-reported or under-reported either their knowledge about or use of folic acid supplements. The teachers may not be representative of all reproductive-aged women; therefore, the generalisability of results is limited.

In addition to these knowledge gaps, this study also identified the participants' stated barriers to folic acid intake; the most frequent barrier (62\%) being the limitation of the participant's information about folic acid, while $44 \%$ mentioned that they did not take folic acid pills specifically because they had not received enough information from their doctor. Similar results were found in a survey of women aged $18-45$ years, who reported that they did not take a vitamin supplement containing folic acid because they felt that they did not need to or rather that they did not receive information about folic acid from their healthcare provider. A study by Coll et al concerning NTDs in the Mediterranean region in 2000 determined that there are three barriers related to poor intake of folic acid: low awareness of the need to take folic acid, folic acid not being prescribed in time and lack of information concerning the advantages of folic acid intake during counselling prior to conception. ${ }^{43}$

Recommendation from large community intervention trial included 247831 women of reproductive age confirmed that periconceptional supplementation with only $0.4 \mathrm{mg}$ of folic acid per day can reduce NTD risk by as much as $81 \%$. ${ }^{44}$ The Chinese government had launched a programme that provides folic acid supplements free for eight women showed that prevalence of NTDs decreased by $22.4 \% .{ }^{45}$ So improving folic acid knowledge is an essential step in promoting the use of folic acid to prevent NTDs. ${ }^{46} 47$ 
Acknowledgements The authors thank all the teachers who took part in this study, and the admin staff and data collectors for their support and guidance.

Contributors LA-M, NAAS and MGA-K designed the study, wrote the primary proposal, managed the data collection, review the literature, fieldwork data management and revised the manuscript. MFS updated the literature review and the discussion and results interpretation, drafted and revised the manuscript, and finalised and submitted the manuscript.

Funding The authors have not declared a specific grant for this research from any funding agency in the public, commercial or not-for-profit sectors.

Competing interests None declared.

Patient consent for publication Obtained.

Ethics approval IRB was obtained from Hamad Medical Corporation.

Provenance and peer review Not commissioned; externally peer reviewed.

Data sharing statement № additional data are available.

Open access This is an open access article distributed in accordance with the Creative Commons Attribution Non Commercial (CC BY-NC 4.0) license, which permits others to distribute, remix, adapt, build upon this work non-commercially, and license their derivative works on different terms, provided the original work is properly cited, appropriate credit is given, any changes made indicated, and the use is non-commercial. See: http://creativecommons.org/licenses/by-nc/4.0/.

\section{REFERENCES}

1. Sharp GF, Naylor LA, Cai J, et al. Assessing awareness, knowledge and use of folic acid in kansas women between the ages of 18 and 44 years. Matern Child Health J 2009;13:814-21.

2. Farley TF, Hambidge SJ, Daley MF. Association of low maternal education with neural tube defects in Colorado, 1989-1998. Public Health 2002;116:89-94.

3. Rajab A, Vaishnav A, Freeman NV, et al. Neural tube defects and congenital hydrocephalus in the Sultanate of Oman. J Trop Pediatr 1998;44:300-3.

4. World Health Organization. Global health estimates (GHE)-Causespecific mortality. 2015 http://www.who.int/healthinfo/global burden_disease/estimates/en/ (Accessed 14th Apr 2015).

5. World Health Organization. Global health estimates (GHE)-Disease burden. 2015 http://www.who.int/healthinfo/global_burden_disease/ estimates/en/index1.html (Accessed 14th Apr 2015).

6. Behrooz A. Prevalence of neural tube defect and its relative factors in south-west of Iran. Pak J Med Sci 2007;23:654-6.

7. Ryan M. Folic acid to prevent neural tube defects: a potential pharmacy initiative with public health implications. Hosp Pharm 2004;39:962-9.

8. Cho S. Folic acid for the prevention of neural tube defects. Pediatrics 1999;104:325-7.

9. International Clearinghouse for Birth Defects Surveillance and Research. International clearinghouse for birth defects surveillance and research. Annual report 2013. Rome: International Clearinghouse for Birth Defects Surveillance and Research, 2013.

10. European Surveillance of Congenital Anomalies. Prevalence tables. Ispra: European Surveillance of Congenital Anomalies, 2015.

11. Yen J, Zoumas-Morse C, Pakiz B, et al. Folate intake assessment: validation of a new approach. J Am Diet Assoc 2003;103:991-1000.

12. Pawlak R, Brown D, Meyer MK, et al. Theory of planned behavior and multivitamin supplement use in Caucasian college females. J Prim Prev 2008;29:57-71.

13. Krishnaswamy K, Madhavan Nair K. Importance of folate in human nutrition. Br J Nutr 2001;85:S115-24.

14. Toriello HV. Professional Practice and Guidelines Committee, American College of Medical Genetics. Folic acid and neural tube defects. Genet Med 2005;7:283-4.

15. Ren A. The prevention of neural tube defects with folic acid. World $J$ Clin Pediatr 2015;4:41-4.

16. Unusan N. Folic acid: Protection against neural tube defects. Engels JV, ed. Focus on birth defects research. New York, NY: Nova Science Publisher, 2006:223-32.

17. Kurtzweil P. How folate can help prevent birth defects. Rockville, MD: Dept. of Health and Human Services, Public Health Service, Food and Drug Administration, 1996.

18. Perry CA, Renna SA, Khitun E, et al. Ethnicity and race influence the folate status response to controlled folate intakes in young women. $J$ Nutr 2004;134:1786-92.
19. Middle East Global Leadership in Wheat Flour Fortification. Flour fortification initiative middle east report. 2012 http://www.ffinetwork. org/regional_activity/middle_east.php

20. Bener A, Al Maadid MG, Al-Bast DA, et al. Maternal knowledge, attitude and practice on folic acid intake among Arabian Qatari women. Reprod Toxicol 2006;21:21-5.

21. de Jong-Van den Berg LT, Hernandez-Diaz S, Werler MM, et al. Trends and predictors of folic acid awareness and periconceptional use in pregnant women. Am J Obstet Gynecol 2005;192:121-8.

22. de Jong-van den Berg LT, de Walle HE, van der Pal-de Bruin KM, et al. Increasing awareness of and behaviour towards periconceptional folic acid consumption in The Netherlands from 1994 to 1995. Eur J Clin Pharmacol 1998;54:329-31.

23. Bonin MM. Knowledge of periconceptional folic acid for the prevention of neural tube defects: the missing links. Arch Fam Med 1998;7:438-42.

24. Pérez-Escamilla R. Periconceptional folic acid and neural tube defects: public health issues. Bull Pan Am Health Organ 1995;29:250-63.

25. Kilker KP. Is knowing half the battle? An examination of the relationship between folic acid knowledge and awareness and daily supplementation with folic acid among 18 to 24 year old women who are not contemplating pregnancy. [Master's Thesis] Atlanta, GA: Georgia State University, 2007.

26. Aronsson CA, Vehik K, Yang J, et al. Use of dietary supplements in pregnant women in relation to sociodemographic factors - a report from The Environmental Determinants of Diabetes in the Young (TEDDY) study. Public Health Nutr 2013;16:1390-402.

27. Pouchieu C, Lévy R, Faure C, et al. Socioeconomic, lifestyle and dietary factors associated with dietary supplement use during pregnancy. PLoS One 2013;8:e70733.

28. Kari JA, Bardisi ES, Baitalmal RM, et al. Folic acid awareness among female college students. Saudi Med J 2008;29:1749-51.

29. Hassan AS, Al-Kharusi BM. Knowledge and use of folic acid among pregnant arabian women residing in Qatar and Oman. Int J Food Sci Nutr 2008;59:70-9.

30. Byrne J, Byrne Y. A population-based survey of knowledge and use of folic acid among Irish women. Drogheda, Ireland: Boyne Research Institute, 2006.

31. Chacko MR, Anding R, Kozinetz CA, et al. Neural tube defects: knowledge and preconceptional prevention practices in minority young women. Pediatrics 2003;112:536-42.

32. Kurdi B, Bener A, Hoffmann G, et al. The pattern of neural tube defects in a highly endogamous society: a 25-year incidence trends. Journal of Pediatric Neurology 2012;10:193-8.

33. Mallard SR, Houghton LA. Folate knowledge and consumer behaviour among pregnant New Zealand women prior to the potential introduction of mandatory fortification. Asia Pac J Clin Nutr 2012;21:440-9.

34. de Lourdes Samaniego-Vaesken M, Alonso-Aperte E, VarelaMoreiras G, et al. Vitamin food fortification today. Food Nutr Res 2012;56:5459.

35. Flour Fortification Initiative. Newsletter dec 2012 anemia and neural tube birth defects decline in Bahrain. 2012 http://www.ffinetwork.org/ about/stay_informed/newsletters/Q4_21012.html

36. Centers for Disease Control and Prevention (CDC). Ten great public health achievements-United States, 2001-2010. MMWR Morb Mortal Wkly Rep 2011;60:619-23.

37. Sen S, Manzoor A, Deviasumathy M, et al. Maternal knowledge, attitude and practice regarding folic acid intake during the periconceptional period. Public Health Nutr 2001;4:909-12.

38. Centers for Disease Control and Prevention (CDC). Prevalence of neural tube defects and folic acid knowledge and consumptionPuerto Rico, 1996-2006. MMWR Morb Mortal Wkly Rep 2008;57:10-13.

39. Sayers GM, Hughes N, Scallan E, et al. A survey of knowledge and use of folic acid among women of child-bearing age in Dublin. $J$ Public Health Med 1997;19:328-32.

40. Meyer RE, Wall A, Morgan A, et al. Knowledge and use of folic acid among north Carolina women. N C Med J 2002;63:18-22.

41. de Walle HE, de Jong-van den Berg LT. Growing gap in folic acid intake with respect to level of education in the Netherlands. Community Genet 2007;10:93-6.

42. Anzaku A. Assessing folic acid awareness and its usage for the prevention of neural tube defects among pregnant women in Jos, Nigeria. Journal of Basic and Clinical Reproductive Sciences 2013;2:13-17.

43. Coll O, Pisa S, Palacio M, et al. Awareness of the use of folic acid to prevent neural tube defects in a mediterranean area. Eur J Obstet Gynecol Reprod Biol 2004;115:173-7. 
44. Berry RJ, Li Z, Erickson JD, et al. Prevention of neural-tube defects with folic acid in China. China-U.S. Collaborative project for neural tube defect prevention. $N$ Engl J Med 1999;341:1485-90.

45. Ministry of Health. Birth defects prevention and control in China. http://www.gov.cn/gzdt/att/att/site1/20120912/1c6f6506c7f811ba cf9301.pdf (Accessed 18th Apr 2014).
46. Murphy BL, Dipietro NA, Kier KL. Knowledge and use of folic acid among college women: a pilot health promotion program led by pharmacy students and faculty. Pharm Pract 2010;8:220-5.

47. Cena ER, Joy AB, Heneman $K$, et al. Learner-centered nutrition education improves folate intake and food-related behaviors in nonpregnant, low-income women of childbearing age. J Am Diet Assoc 2008;108:1627-35. 